\title{
Knowledge Attitude and Practice Regarding Cryosurgery among Dental Students
}

\author{
Research Article
}

\author{
Abhishek Naram ${ }^{1}$, Dinesh Prabu $^{2 *}$, Deepak S
}

${ }^{1}$ Saveetha Dental College and Hospitals, Saveetha Institute of Medical and Technical Sciences(SIMATS), Saveetha University, Chennai 600 077, Tamil Nadu, India.

${ }^{2}$ Senior Lecturer, Department of Oral and Maxillofacial Surgery, Saveetha Dental College and Hospitals, Saveetha Institute of Medical and Technical Sciences(SIMATS), Saveetha University, Chennai 600 077, Tamil Nadu, India.

${ }^{3}$ Senior Lecturer, Department of Conservative Dentistry and Endodontics, Saveetha Dental College and Hospitals, Saveetha Institute of Medical and Technical Sciences(SIMATS), Saveetha University, Chennai 600 077, Tamil Nadu, India.

\section{Abstract}

Cryosurgery is the use of extreme cold produced by liquid nitrogen (or argon gas) to destroy the abnormal tissue. Its use is increasing in oral cavity. The oral mucosa, because of its characteristics of humidity and smoothness, is an ideal site for its technique. It shows a very good aesthetic result and it may be either the first choice or an alternative option to conventional surgery. Aim of the study is to create awareness and to evaluate the knowledge and attitude on cryosurgery among dental students. practice regarding COVID-19 and infection control among dental students. Data was collected through google forms. Responses were analysed and statistical data is analysed by using spss software. In the present study $91 \%$ of the participants are aware of the cryosurgery $78 \%$ of the subjects selected liquid nitrogen as the common cryogen used in cryosurgery. $68 \%$ of the participants said they will prefer cryosurgery to destroy abnormal tissue and $32 \%$ of the study population disagreed with it. $88 \%$ of the participants are willing to attend a workshop on cryosurgery. Knowledge, attitude among Dental students regarding cryosurgery is inadequate. Majority of students have good knowledge on material used for cryosurgery.Most of the students were also aware that cryosurgery is a painless treatment. But unaware about the indications and contraindications of cryosurgery.

Keywords: Cryosurgery; Knowledge; Tumours; Liquid Nitrogen.

\section{Introduction}

Cryosurgery is a controlled and targeted destruction of diseased tissue by the application of low temperatures. The beneficial effects of cold as a therapeutic agent are known for an extended time, with ancient population conscious of the reinvigorating effects of cold water either taken orally or used for baths. The use of cold, mainly locally, still remains in our daily common activities. It is a simple, cost effective, efficacious, and esthetically acceptable modality for the treatment of various dermatoses. It is a very safe, inexpensive, reproducible, repeatable, and simple office procedure. It requires a short preparation time, is a suture less procedure with minimal risk of infection and no anesthesia is usually required. It may be performed at any age, including in old patients with pacemakers, in whom electrocautery is contraindicated, patients on anticoagulants, patients allergic to esthetic agents, [1]. patients with transmissible conditions such as human immunodeficiency virus and hepatitis, during pregnancy, and over most of the body sites. It provides high healing rates even in difficult areas, with excellent cosmetic results if performed appropriately. In view of all these advantages, it is regarded as a treatment of choice by many dermatologists for various benign and malignant dermatoses $[2,3]$. On spraying the cryogen, there is a rapid transfer of heat from the tissue to the cryogen, with ice formation in the extracellular compartment. The extracellular solutes are concentrated, setting up an osmotic gradient, with the movement of fluid extracellularly and concentration of solutes within the cell leading to cell damage. The ice crystals also damage the cell membrane mechanically [4]. Moreover, intracellular ice formation occurs, damaging organelles such as mitochondria and endoplasmic reticulum. There are severe vasoconstriction and endothelial damage because of cold temperature resulting in platelet

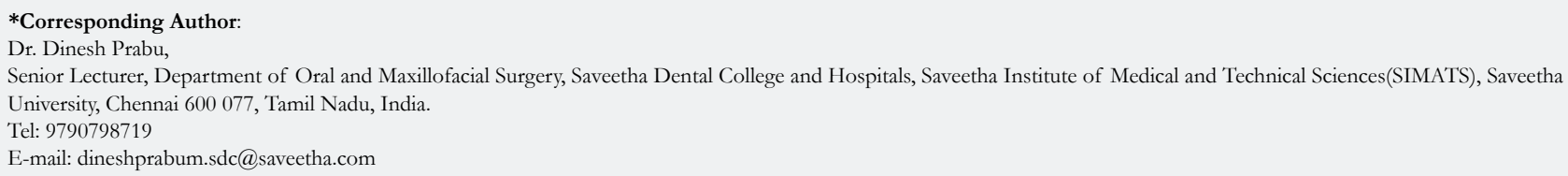

Citation: Abhishek Naram, Dinesh Prabu, Deepak S. Knowledge Attitude and Practice Regarding Cryosurgery among Dental Students. Int J Dentistry Oral Sci. 2019;S2:02:0012:53-59. doi: http://dx.doi.org/10.19070/2377-8075-SI02-020012

Copyright: Dinesh Prabu' 2019 . This is an open-access article distributed under the terms of the Creative Commons Attribution License, which permits unrestricted use, distribution and reproduction in any medium, provided the original author and source are credited. 
aggregation and microthrombi formation, producing ischemic necrosis of the tissue. There is inflammation in response to cell death causing further destruction [5-7].

Cryosurgery is often used to treat conditions that involve irritation of an isolated nerve. In general, such conditions include benign nerve growths (neuromas) and pinched nerves (nerve entrapments), vascular lesions, benign tumors, acne, pigmented lesions, viral infections, inflammatory dermatoses, and infectious dermatoses. Premalignant and malignant tumors are also being treated by cryosurgery $[8,9]$. Complications include local pain more in the periungual area, temple, plantar areas, eyelids, lips, mucous membranes, tingling and numbness, especially on the fingers, edema, especially on the eyelids, lips, labia, and prepuce, more in infants and the elderly, cryoblister formation, and syncope (vasovagal reaction) in anxious patients along with occasional headache (migraine type) after the treatment of the head and neck area [10]. Common protracted complication includes hypopigmentation, especially in dark-skinned individuals, atrophic scar, and local hypoesthesia due to nerve damage, especially in areas, where the nerves lie superficially, such as the sides of fingers, angle of jaw, post-auricular area, sides of tongue and ulnar fossa of elbow, milia formation, and cicatricial alopecia $[10,11]$. Absolute contraindications include blood dyscrasias of unknown origin, cold intolerance, Raynaud's disease, cold urticaria, cryoglobulinemia, lesions in areas of compromised circulation, sclerosing basal cell carcinoma (BCC), or recurrent BCC or squamous cell carcinoma located in high-risk areas such as the temple or nasolabial folds [10-12]. Previously our team had conducted numerous clinical trials and invitro studies [13-27] over the past 5 years now we are focussing on surveys the idea of this survey stemmed from the current interest in our community. So the aim of our survey was to access the knowledge, attitude and awareness of cryosurgery among dental students.

\section{Materials and Methods}

An online survey was done with the structured questionnaire based on knowledge, attitude, practice survey among the dental students regarding cryosurgery.

\section{Ethical approval}

Ethical permission and approval for the project was obtained from the Institutional Review Board of Saveetha Institute of Medical and Technical Sciences, Chennai, India on Date 25/04/2020.

\section{Sampling and data collection}

This cross sectional survey was conducted among 100 dental undergraduate students who were in 3rd year, 4th year and interns. A structured questionnaire consisting of 21 questions was shared online and 100 responses were obtained. Data entry was made in the Excel sheet, SPSS software was used to analyze the data. The advantages of online surveys is that it was economical, easy to create, wide reach and disadvantage is repeated and incomplete answers.

\section{Statistical analysis}

The descriptive statistics were used to determine the responses given by the participants. Statistical analysis, Chi square test was used to assess the association between the year of study and the responses. And the results are depicted in the form of a bar chart.

\section{Results and Discussion}

In the present study [fig 1] there are a total of 100 participants there are 35 males and 65 females [fig 2]. 81\% of the participants are aware of the cryosurgery. [fig 4 ] $75 \%$ of the subjects selected liquid nitrogen as the common cryogen used in cryosurgery whereas 25\% selected argon and carbon dioxide.[fig 5] $68 \%$ of the study participants said -19.6 degrees centigrade is the operating temperature of liquid based cryoprobe. [fig 6] 51\% of the participants said -127 degrees as the boiling point of the cryogen. [fig 7] $63 \%$ of the participants aren't aware that the spray freez-

Figure 1. Bar graph represents distribution of gender and frequency. $X$ axis represents gender and $y$ axis represents percentage of responses out of 100 respondents $35 \%$ are male (yellow)and $65 \%$ are female(grey).

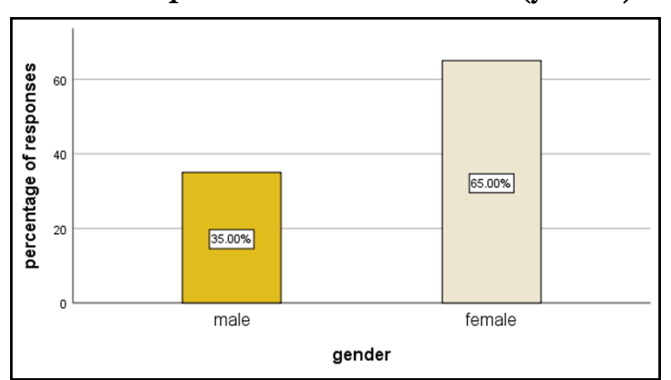

Figure 2. Bar graph represents frequency of responses for the question "Are you aware about cryosurgery" (X axis represents gender and $\mathrm{Y}$ axis represents percentage of responses) higher percentage of respondents(91\%) said yes (blue).

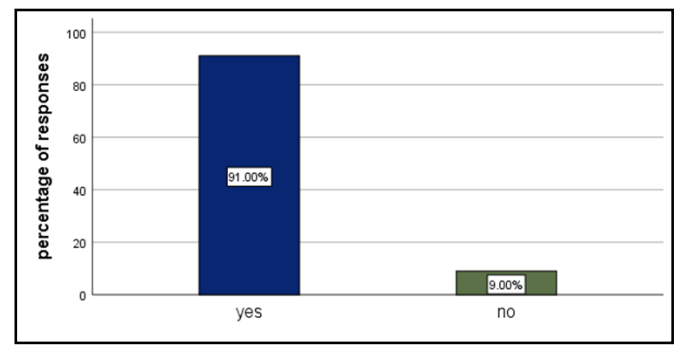


Figure 3. Bar graph represents frequency of responses for the question "if yes do you practice cryosurgery" (X axis represents gender and $\mathrm{Y}$ axis represents percentage of responses higher percentage of respondents (98\%) said yes (blue).

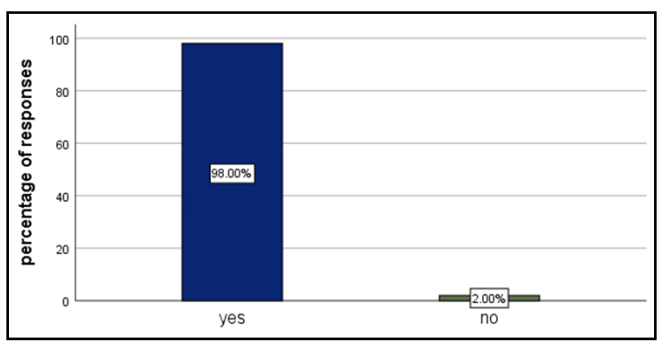

Figure 4. Bar graph represents frequency of responses for the question. Which is the most common material used in cryosurgery" ( $\mathrm{X}$ axis represents gender and $\mathrm{Y}$ axis represents percentage of responses) higher percentage of respondents (78\%) said liquid nitrogen.

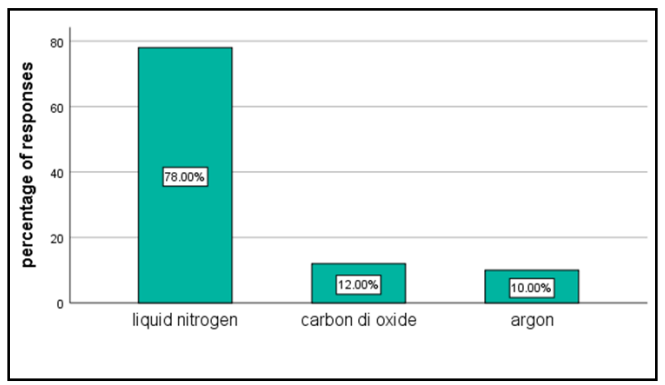

Figure 5. Bar graph represents frequency of responses for the question "what is the temperature at which liquid nitrogen based cryoprobe operates" (X axis represents gender and $\mathrm{Y}$ axis represents percentage of responses) higher percentage of respondents $(68 \%)$ said -19.6 degrees.

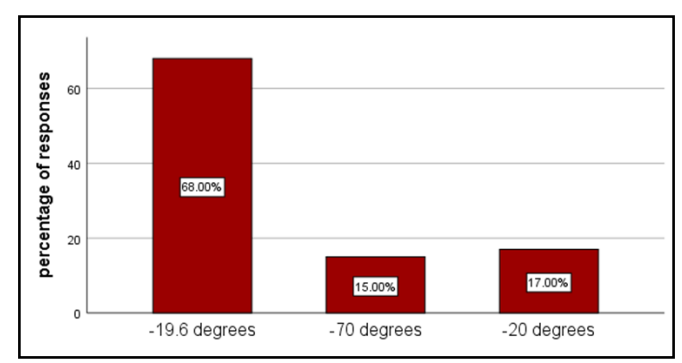

Figure 6. Bar graph represents frequency of responses for the question What is the boiling point of cryogen used in cryosurgery" (X axis represents gender and $\mathrm{Y}$ axis represents percentage of responses) higher percentage of respondents $(51 \%)$. said -127 degrees.

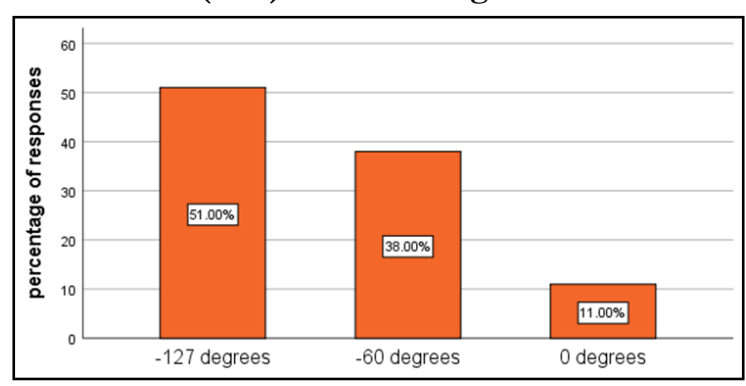

Figure 7. Bar graph represents frequency of responses for the question. "Which of the following technique is the most destructive type in cryosurgery" ( $\mathrm{X}$ axis represents gender and $\mathrm{Y}$ axis represents percentage of responses) higher percentage of respondents $(42 \%)$ said -probe freezing.

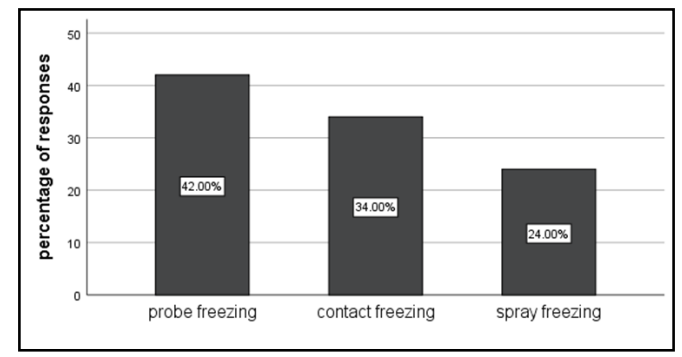


Figure 8. Bar graph represents frequency of responses for the question "What is the pressure of spray in spray freezing technique" ( $\mathrm{X}$ axis represents gender and $\mathrm{Y}$ axis represents percentage of responses higher percentage of respondents $(51 \%)$. said 540 psi.

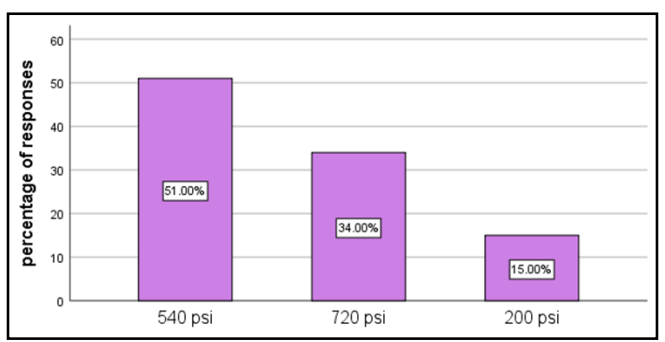

Figure 9. Bar graph represents frequency of responses for the question "Which of the following are the indications of cryotherapy" ( $\mathrm{X}$ axis represents gender and $\mathrm{Y}$ axis represents percentage of responses) higher percentage of respondents (38\%) said vascular leisions.

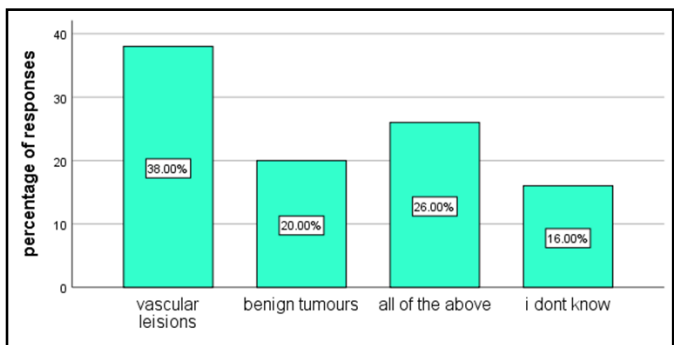

Figure 10. Bar graph represents frequency of responses for the question "What are the acute complications of cryosurgery" ( $\mathrm{X}$ axis represents gender and $\mathrm{Y}$ axis represents percentage of responses) higher percentage of respondents (54\%) said $\mathrm{i}$ dont know.

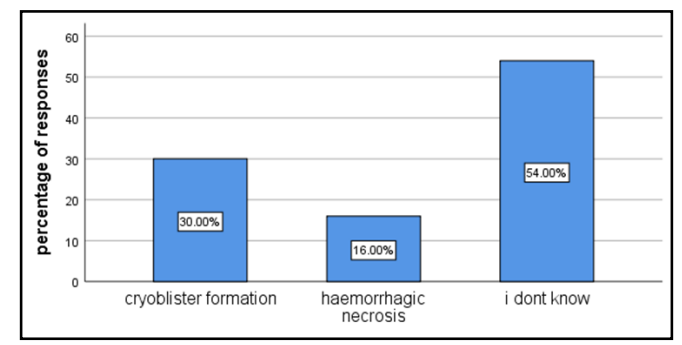

Figure 11. Bar graph represents frequency of responses for the question "What are the protracted (common) complications of cryotherapy" (X axis represents gender and $\mathrm{Y}$ axis represents percentage of responses) higher percentage of respondents $(34 \%)$ said local pain.

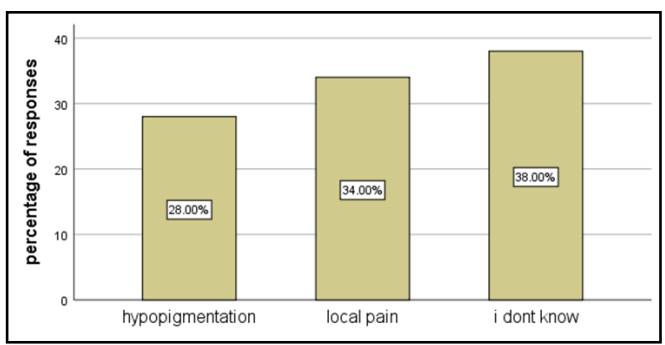

Figure 12. Bar graph represents frequency of responses for the question "What is the absolute contra indications of cryosurgery" ( $\mathrm{X}$ axis represents gender and $\mathrm{Y}$ axis represents percentage of responses) higher percentage of respondents (36\%) said i dont know.

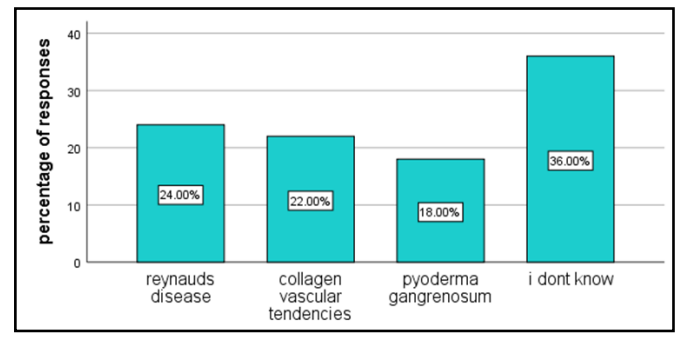


Figure 13. Bar graph represents frequency of responses for the question "What is the relative contraindications of cryosurgery" (X axis represents gender and $\mathrm{Y}$ axis represents percentage of responses) higher percentage of respondents (42\%) said i dont know.

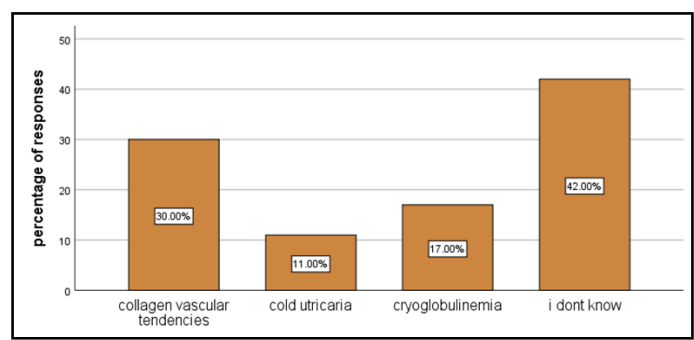

Figure 14. Bar graph represents the association of responses between male and female. $\mathrm{X}$ axis represents gender and $\mathrm{Y}$ axis represents no of responses. When asked "Would you prefer cryosurgery to destroy abnormal tissues" higher number of females have responded yes (blue). Pearson chi square test was done and it gave a $p$ value of 0.719 which is $>0.05$ hence the results were not statistically significant.

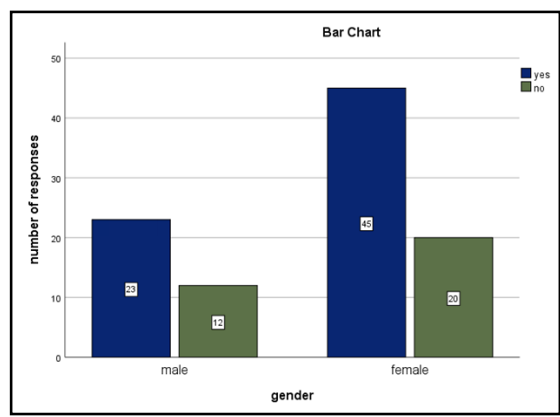

Figure 15. Bar graph represents frequency of responses for the question "Are you aware cryosurgery can be used to treat malignant and premalignant leision ( $\mathrm{X}$ axis represents gender and $\mathrm{Y}$ axis represents percentage of responses) higher percentage of respondents (54\%) said yes (blue).

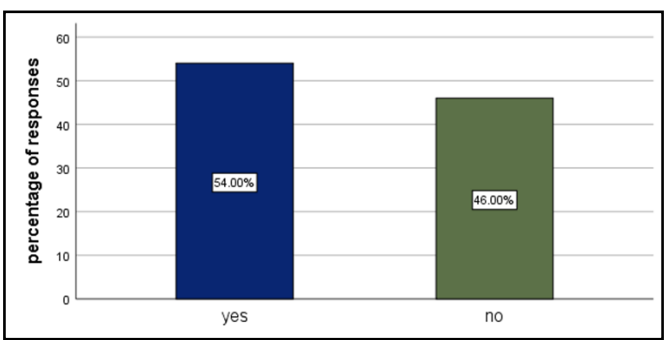

Figure 16. Bar graph represents frequency of responses for the question "The cryosurgery tip in spot freeze technique should be placed at what distance from target leision" ( $\mathrm{X}$ axis represents gender and $\mathrm{Y}$ axis represents percentage of responses) higher percentage of respondents $(38 \%)$ said 1 to $1.5 \mathrm{~cm}$.

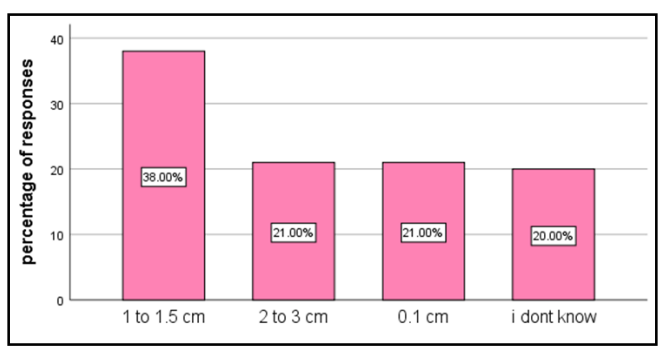

Figure 17. Bar graph represents frequency of responses for the question "Destruction of the benign lesions requires temperature of at least" ( $\mathrm{X}$ axis represents gender and $\mathrm{Y}$ axis represents percentage of responses) higher percentage of respondents $(47 \%)$ said between -100 to -150 degrees celsius.

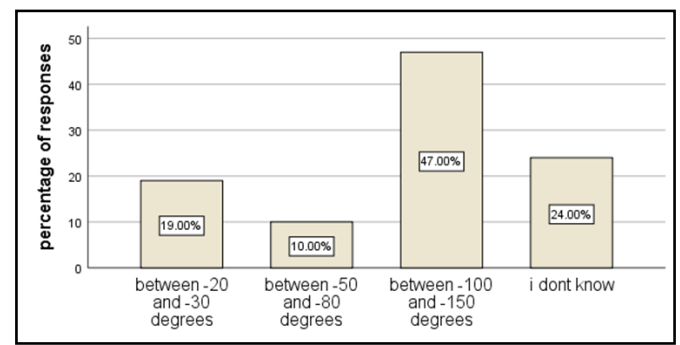


ing is the most destructive type of cryosurgery only $37 \%$ of the participants selected probe freezing is the most destructive type in cryosurgery. [fig 8] 51\% of the subjects said that the 540 psi is the pressure of spray in the spray freezing technique. [fig 9] only $26 \%$ of the participants selected correct answer for the indications of the cryosurgery. [fig 10] majority of the participants said they are not aware of the acute complications of cryosurgery. [fig 11] $38 \%$ of the students said that they are not aware of the protracted complications of cryosurgery. [fig 12] Only $25 \%$ of the participants said raynauds disease is the absolute contraindication in cryosurgery $75 \%$ of the participants selected the wrong op- tion for the contraindications.[fig 13] $42 \%$ of the participants said they do not know the relative contraindications of the cryosurgery.[fig14] $77 \%$ of the participants said they will prefer cryosurgery to destroy abnormal tissue and $23 \%$ of the study population disagreed with it. [fig 15] 69\% of the study participants agreed with the fact that cryosurgery can be used to treat malignant and premalignant lesion and 31\% disagreed with the fact.. [fig 16] $38 \%$ of the total study participants said the cryosurgery tip should be placed 1 to $1.5 \mathrm{~cm}$ distance from the target leision. [fig 17] $47 \%$ of the study participants selected destruction of benign lesions require a temperature of about -100 to -150 degrees centigrade.

Figure 18. Bar graph represents frequency of responses for the question"What is the effective temperature at which malignant tissues destroy" ( $\mathrm{X}$ axis represents gender and $\mathrm{Y}$ axis represents percentage of responses) higher percentage of respondents $(46 \%)$ said $\mathrm{i}$ dont know.

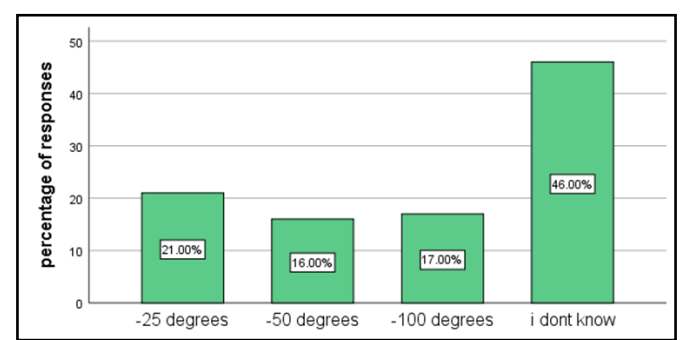

Figure 19. Bar graph represents frequency of responses for the question "What is the operating temperature of whole body cryotherapy" (X axis represents gender and $\mathrm{Y}$ axis represents percentage of responses) higher percentage of respondents $(39 \%)$ said between -110 to -140 degrees celsius.

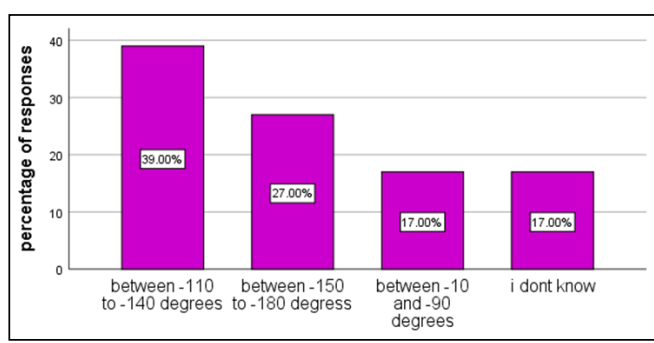

Figure 20. Bar graph represents frequency of responses for the question "Areas where cryotherapy is not recommended" ( $\mathrm{X}$ axis represents gender and $\mathrm{Y}$ axis represents percentage of responses) higher percentage of respondents (35\%) said corners of the eye and skin overlying nerves.

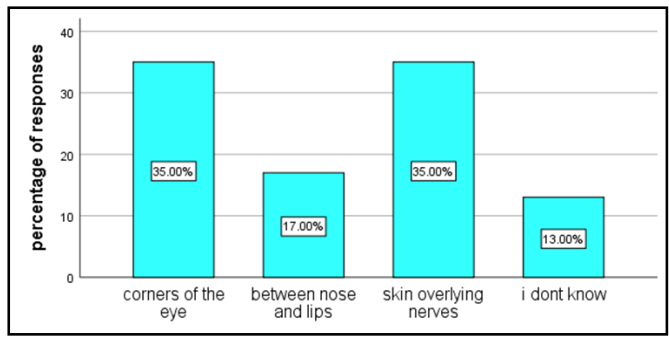

Figure 21. bar graph represents the distribution of responses between male and female. $\mathrm{X}$ axis represents gender and $\mathrm{Y}$ axis represents no of responses. When asked are you willing to attend a hands on workshop on cryosurgery "higher number of males and females have responded yes (blue).Pearson chi square test was done and it gave a p value of 0.547 which is $>0.05$ hence the results were not statistically significant.

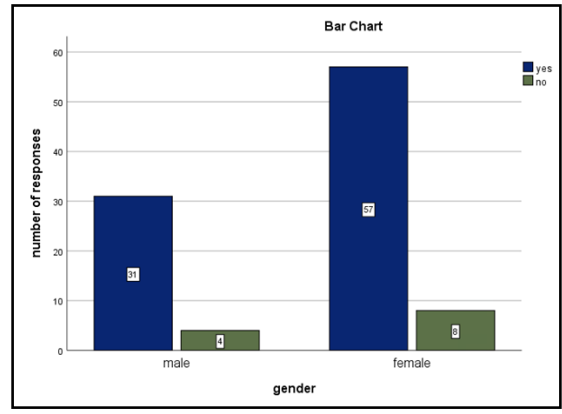


[fig 18] 46\% of the students said they do not know the effective temperature at which malignant tissues get destroyed [ fig 19] 39\% of the participants said the operating temperature of the whole body cryotherapy is between -110 to -140 degrees centigrade. [fig 20] majority of the students said skin overlying nerves and the corners of the eye are the areas where cryosurgery is not recommended. [fig21] $86 \%$ of the participants are willing to attend a workshop on cryosurgery.

Health professionals play a pivotal role in providing knowledge regarding oral health and its significance among the general public. Dental students should possess a high level of the awareness of both medicinal and practical knowledge. Cryosurgery is more often used in modern rehabilitation for the treatment of various diseases [6]. About $95.3 \%$ cure rate was achieved in the treatment of facial BCC by Mallon and Dawber and Noah and Scheinfeld successfully treated verruca vulgaris [28] depicting the various application of cryogens which dentists and other medical professionals must be aware. Cryosurgery competes well on morbidity and cosmetic outcome and is the quickest, easiest, cheapest, and most readily available of the treatment options [29]. This technique can be used, even by those inexperienced in cryosurgery, to achieve predictable success rates. A study was conducted by Asrani et al., [30] evaluating the efficacy of cryosurgery in the management of oral mucosal lesions concluded, cryosurgery is overall a better modality for the treatment of oral lesions as it is more reasonable with adequate success. The procedure is relatively more stable and has shown to have a faster recovery. Another study conducted by Murugadoss et al. [31] concluded cryosurgery with its ability to produce very low temperatures causes effective tissue destruction. It has been utilized for oral cavity lesions of the infants, elderly patients, and also immunocompromised patients. With a wide variety of cryogens that have come in the market and by combining these cryogens, better treatment protocols and freezing times have been established, producing excellent results. With cryosurgery becoming one of the most chosen treatment modalities for various oral lesions, it is necessary for the dentists to have complete knowledge of them.

\section{Conclusion}

The present study concluded that most of the subjects had limited knowledge regarding cryosurgery, yet there were significant knowledge gaps in some of the important aspects like indications contraindications types of techniques in cryosurgery. These findings clearly indicate the importance of improving subjects knowledge regarding cryosurgery via health education and training programs through webinars for dentists.

\section{References}

[1]. Erkens AM, Kuijpers RJ, Knottnerus JA. An end to office hours for warts? A randomized study of the effectiveness of liquid nitrogen and of the Histofreezer. Ned Tijdschr Geneeskd. 1991 Feb 1;135(5):171-4.

[2]. Holt PJ. Cryotherapy for skin cancer: results over a 5-year period using liquid nitrogen spray cryosurgery. Br J Dermatol. 1988 Aug;119(2):231-40.Pubmed PMID: 3166941

[3]. Kuflik EG. Cryosurgery for skin cancer: 30-year experience and cure rates. Dermatol Surg. 2004 Feb;30(2 Pt 2):297-300.Pubmed PMID: 14871224

[4]. Mayeaux Jr EJ, Harper MB, Barksdale W, Pope JB. Noncervical human papillomavirus genital infections. Am Fam Physician. 1995 Sep 1;52(4):1137-46.

[5]. Michel S, Wlotzke U, Hohenleutner U, Landthaler M. Laser and cryotherapy of hemangioma in infants in a direct comparison. Der Hautarzt; Zeitschrift fur Dermatologie, Venerologie, und verwandte Gebiete. 1998 Mar;49(3):192-6.
[6]. Mallon E, Dawber R. Cryosurgery in the treatment of basal cell carcinoma. Assessment of one and two freeze-thaw cycle schedules. Dermatol Surg. 1996 Oct;22(10):854-8.Pubmed PMID: 9246168.

[7]. Zouboulis CC, Blume U, Büttner P, Orfanos CE. Outcomes of cryosurgery in keloids and hypertrophic scars. A prospective consecutive trial of case series. Arch Dermatol. 1993 Sep;129(9):1146-51.Pubmed PMID: 8363398.

[8]. Zacarian SA. Cryosurgery of cutaneous carcinomas. An 18-year study of 3,022 patients with 4,228 carcinomas. J Am Acad Dermatol. 1983 Dec;9(6):947-56. Pubmed PMID: 6643791.

[9]. Sinclair RD, Dawber RP. Cryosurgery of malignant and premalignant diseases of the skin: a simple approach. Australas J Dermatol. 1995 Aug;36(3):133-42. Pubmed PMID: 7487739.

[10]. On Cryosurgery TF. Guidelines of care for cryosurgery. J Am Acad Dermatol. 1994 Oct 1;31(4):648-53.

[11]. Bleakley CM, Bieuzen F, Davison GW, Costello JT. Whole-body cryotherapy: empirical evidence and theoretical perspectives. Open Access J Sports Med. 2014 Mar 10;5:25-36.Pubmed PMID: 24648779.

[12]. Bouzigon R, Grappe F, Ravier G, Dugue B. Whole-and partial-body cryostimulation/cryotherapy: Current technologies and practical applications. J. Therm. Biol. 2016 Oct 1;61:67-81.

[13]. Jesudasan JS, Wahab PU, Sekhar MR. Effectiveness of $0.2 \%$ chlorhexidine gel and a eugenol-based paste on postoperative alveolar osteitis in patients having third molars extracted: a randomised controlled clinical trial. $\mathrm{Br} J$ Oral Maxillofac Surg. 2015 Nov;53(9):826-30.Pubmed PMID: 26188932.

[14]. Christabel A, Anantanarayanan P, Subash P, Soh CL, Ramanathan M, Muthusekhar MR, et al. Comparison of pterygomaxillary dysjunction with tuberosity separation in isolated Le Fort I osteotomies: a prospective, multi-centre, triple-blind, randomized controlled trial. Int J Oral Maxillofac Surg. 2016 Feb;45(2):180-5.Pubmed PMID: 26338075

[15]. Packiri S, Gurunathan D, Selvarasu K. Management of Paediatric Oral Ranula: A Systematic Review. J Clin Diagn Res. 2017 Sep;11(9):ZE06-ZE09.Pubmed PMID: 29207849.

[16]. Mp SK. Relationship between dental anxiety and pain experience during dental extractions. Asian J Pharm Clin Res. 2017;10(3):458-61.

[17]. Patil SB, Durairaj D, Suresh Kumar G, Karthikeyan D, Pradeep D. Comparison of Extended Nasolabial Flap Versus Buccal Fat Pad Graft in the Surgical Management of Oral Submucous Fibrosis: A Prospective Pilot Study. J Maxillofac Oral Surg. 2017 Sep;16(3):312-321.Pubmed PMID: 28717289.

[18]. Rao TD, Kumar MP. Analgesic Efficacy of Paracetamol Vs Ketorolac after Dental Extractions. Res J Pharm Technol. 2018;11(8):3375-9.

[19]. Abhinav RP, Selvarasu K, Maheswari GU, Taltia AA. The Patterns and Etiology of Maxillofacial Trauma in South India. Ann Maxillofac Surg. 2019 JanJun;9(1):114-117.Pubmed PMID: 31293938.

[20]. Kumar S. The emerging role of botulinum toxin in the treatment of orofacial disorders: literature update. Asian J Pharm Clin Res. 2017;10(9):21-9.

[21]. RAHMAN R, MP SK. KNOWLEDGE, ATTITUDE, AND AWARENESS OF DENTAL UNDERGRADUATE STUDENTS REGARDING HUMAN IMMUNODEFICIENCY VIRUS/ACQUIRED IMMUNODEFICIENCY SYNDROME PATIENTS. Asian J Pharm Clin Res. 2017;10(5):175-80.

[22]. Kumar S, Snena S. Knowledge and awareness regarding antibiotic prophylaxis for infective endocarditis among undergraduate dental students. Asian J Pharm Clin Res. 2016;9:154-9.

[23]. Patturaja K, Pradeep D. Awareness of Basic Dental Procedure among General Population. Res J Pharm Technol. 2016;9(9):1349-51.

[24]. Vijayakumar Jain S, Muthusekhar MR, Baig MF, Senthilnathan P, Loganathan S, Abdul Wahab PU, et al. Evaluation of Three-Dimensional Changes in Pharyngeal Airway Following Isolated Lefort One Osteotomy for the Correction of Vertical Maxillary Excess: A Prospective Study. J Maxillofac Oral Surg. 2019 Mar;18(1):139-146.Pubmed PMID: 30728705.

[25]. Chagani MM, Manji KP, Manji MP, Sheriff FG. Healthcare workers' knowledge, attitudes, practices on post exposure prophylaxis for HIV in Dar es Salaam. Tanzania Medical Journal. 2011;25(2):33-8.

[26]. Santhoshkumar MP. Knowledge, attitude and practices of dental students toward dental management of patients on antiplatelet therapy. Asian J Pharm Clin Res. 2016;9:270-6.

[27]. Subramanyam D, Gurunathan D, Gaayathri R, Vishnu Priya V. Comparative evaluation of salivary malondialdehyde levels as a marker of lipid peroxidation in early childhood caries. Eur J Dent. 2018 Jan-Mar;12(1):67-70.Pubmed PMID: 29657527.

[28]. Scheinfeld NS. Treatment of verruca vulgaris. Skinmed. 2006;5(1):37-8.

[29]. Graham GF, Clark LC. Statistical analysis in cryosurgery of skin cancer. Clin Dermatol. 1990 Jan 1;8(1):101-7.

[30]. Askarian M, Malekmakan L, Memish ZA, Assadian O. Prevalence of needle stick injuries among dental, nursing and midwifery students in Shiraz, Iran. GMS Krankenhhyg Interdiszip. 2012;7(1).

[31]. Murugadoss P, Thulasidoss GP, Andavan G, Kumar RK. Advent and implications of cryosurgery in maxillofacial mucosal lesions. SRM J Res Dent Sci. 2016 Oct $1 ; 7(4): 242$. 